\title{
Stellate ganglion block as an intervention in refractory eosinophilic granulomatosis with polyangiitis: a case report
}

\author{
Danxu Ma ${ }^{1 \dagger}$, Yuting Xue ${ }^{2 \dagger}$, Rong Shi ${ }^{1}$, Yinan Yang ${ }^{1}$, Huili $\mathrm{Li}^{1}$, Xuhua Shi ${ }^{3}$, Li Wang ${ }^{4}$ and Yun Wang ${ }^{1 *}$
}

\begin{abstract}
Background: Eosinophilic granulomatosis with polyangiitis (EGPA) is a rare vasculitis. Although glucocorticoid therapy with or without immunosuppressants leads to remission in the majority of cases, most EGPA patients remain dependent on glucocorticoid therapy and experience frequent relapses. Here, we report a case of refractory EGPA which responded to stellate ganglion blocks (SGBs).

Case presentation: A 32-year-old woman with aggravated wheezing, purpura, numbness of multiple fingers, and epigastric and abdominal pain was referred to our clinic. Laboratory and radiographic studies led to the diagnosis of EGPA. After an initial favorable response to glucocorticoid and immunosuppressant therapy, she experienced a relapse during a glucocorticoid taper. We found that SGB brought symptomatic relief and impeded disease progression. The mechanism of action of SGB on EGPA is undetermined, but may be related to vasodilation, immune modulation, and central nervous system regulation.
\end{abstract}

Conclusions: This report not only proposes a novel treatment modality for EGPA, but also provides a clinical reference point for further in-depth studies of SGB in multiple immune-linked disorders.

Keywords: Eosinophilic granulomatosis with polyangiitis, EGPA, Stellate ganglion block

\section{Background}

Eosinophilic granulomatosis with polyangiitis (EGPA), formerly named Churg-Strauss syndrome, is a rare autoimmune disorder characterized by asthma, sinusitis, pulmonary infiltrates, neuropathy, and eosinophilic vasculitis of one or more end-organs. Pathogenesis is thought to involve eosinophilic tissue and vascular infiltration and inflammation induced by a variety of mediators. Although glucocorticoid therapy with or without immunosuppressants leads to remission in the majority of cases, EGPA patients remain dependent

\footnotetext{
*Correspondence: wangyun129@ccmu.edu.cn

${ }^{\dagger}$ Danxu Ma and Yuting Xue contributed equally to this work

${ }^{1}$ Department of Anesthesiology and Pain Medicine, Beijing Chaoyang Hospital, Capital Medical University, Beijing, China

Full list of author information is available at the end of the article
}

on glucocorticoid therapy and experience frequent relapses. Given the side effects of prolonged and highdose glucocorticoid and immunosuppressive regimens, additional effective therapies are needed [1-4].

Stellate ganglion block (SGB) has been used for the management of sympathetically mediated pain and ischemic disorders of the upper extremity, chest, head and face that include complex regional pain syndrome, postherpetic neuralgia, migraine, tinnitus, and refractory angina [5]. A few case reports have described successful SGB therapy of ischemia and pain caused by vascular complications of rheumatic conditions such as Raynaud disease [6, 7], temporal arteritis [8], and vasculitis induced by systemic lupus erythematosus [9]. Furthermore, SGB has also been used with some success in treating bronchial asthma [10]. Here, we report a case of refractory EGPA with asthma that responded to SGBs. original author(s) and the source, provide a link to the Creative Commons licence, and indicate if changes were made. The images or other third party material in this article are included in the article's Creative Commons licence, unless indicated otherwise in a credit line to the material. If material is not included in the article's Creative Commons licence and your intended use is not permitted by statutory regulation or exceeds the permitted use, you will need to obtain permission directly from the copyright holder. To view a copy of this licence, visit http://creativecommons.org/licenses/by/4.0/. The Creative Commons Public Domain Dedication waiver (http://creativeco mmons.org/publicdomain/zero/1.0/) applies to the data made available in this article, unless otherwise stated in a credit line to the data. 


\section{Case presentation}

A 32-year-old woman complaining of aggravated wheezing, bruising, and numbness of multiple fingers presented to our rheumatology and immunology department. She reported epigastric and right upper abdominal pain of 6 months duration. She had suffered from bronchial asthma for 5 years, treated with inhaled corticosteroid therapy. Physical findings included purpura (Fig. 1a). Laboratory tests revealed increased leukocytosis $\left(15.59 \times 10^{3} / \mu \mathrm{L}\right) \quad$ with eosinophilia $\left(7.96 \times 10^{3} / \mu \mathrm{L}, \quad 51.1 \%\right)$ and elevated erythrocyte sedimentation rate (ESR) $(30 \mathrm{~mm} / \mathrm{h})$, C-reactive protein $(0.54 \mathrm{mg} / \mathrm{dL})$, immunoglobulin $(\mathrm{Ig}) \mathrm{E}(808 \mathrm{kU} / \mathrm{L}), \operatorname{IgG} 4$ $(2028 \mathrm{mg} / \mathrm{L})$, and rheumatoid factor $(176 \mathrm{IU} / \mathrm{mL})$. Negative studies included anti-nuclear antibodies; and cytoplasmic-, perinuclear-, proteinase-3-, and myeloperoxidase-anti-neutrophil cytoplasmic antibodies. Computed tomography of the chest disclosed a subpleural patchy shadow in the posterior basal segment of the right lower lobe (Fig. 1b). She was diagnosed with EGPA according to the 1990 classification criteria of the American College of Rheumatology [4], and began therapy with daily doses of prednisone acetate $30 \mathrm{mg}$ and cyclophosphamide $50 \mathrm{mg}$ given orally. All symptoms resolved quickly, and eosinophilia and ESR returned to normal. Four weeks later, when prednisone acetate was reduced to $27.5 \mathrm{mg}$, she developed a mild dry nocturnal cough, and experienced a relapse of respiratory, digestive, and neurological symptoms after another 2 weeks, when the daily dose of prednisone acetate was reduced to $25 \mathrm{mg}$. Consequently, she received supplemental betamethasone $7 \mathrm{mg}$ by intramuscular injection that resulted in a remission of only 1 week's duration.

Considering that SGB is an effective treatment for asthma and multiple ischemic conditions, an experimental ultrasound-guided unilateral SGB was planned. The patient was positioned supine with the neck turned to the right. The skin was disinfected with iodophor, and a high frequency $(4-12 \mathrm{MHz})$ lineararray ultrasound transducer (TUR200, Tuoren Medical Device Co., Ltd. Henan, China) covered with a sterile sleeve was placed transversely at the left anterior cervical region (Fig. 2a) to identify relevant anatomic structures that included the C6 transverse process, carotid artery, internal jugular vein, longus colli muscle, prevertebral fascia, vertebral artery, and inferior thyroid artery. A 25 -gauge needle was inserted in-plane and the needle tip was placed between the fascia investing the longus colli muscle and the prevertebral fascia, and $2 \mathrm{~mL} 1 \%$ lidocaine was injected (Fig. 2b).

Immediately after the block, Horner's syndrome occurred, and she reported simultaneous resolution of all symptoms, such as wheezing, epigastric and abdominal pain, and numbness of the fingers. SGB was repeated every 2 days, alternating between left and right aspects of the neck, for completion of a 7-procedure treatment course. Prednisone acetate was successfully tapered to $22.5 \mathrm{mg}$ daily without symptomatic relapse. Furthermore, no inhaled corticosteroids were required, and improved mood and sleep were
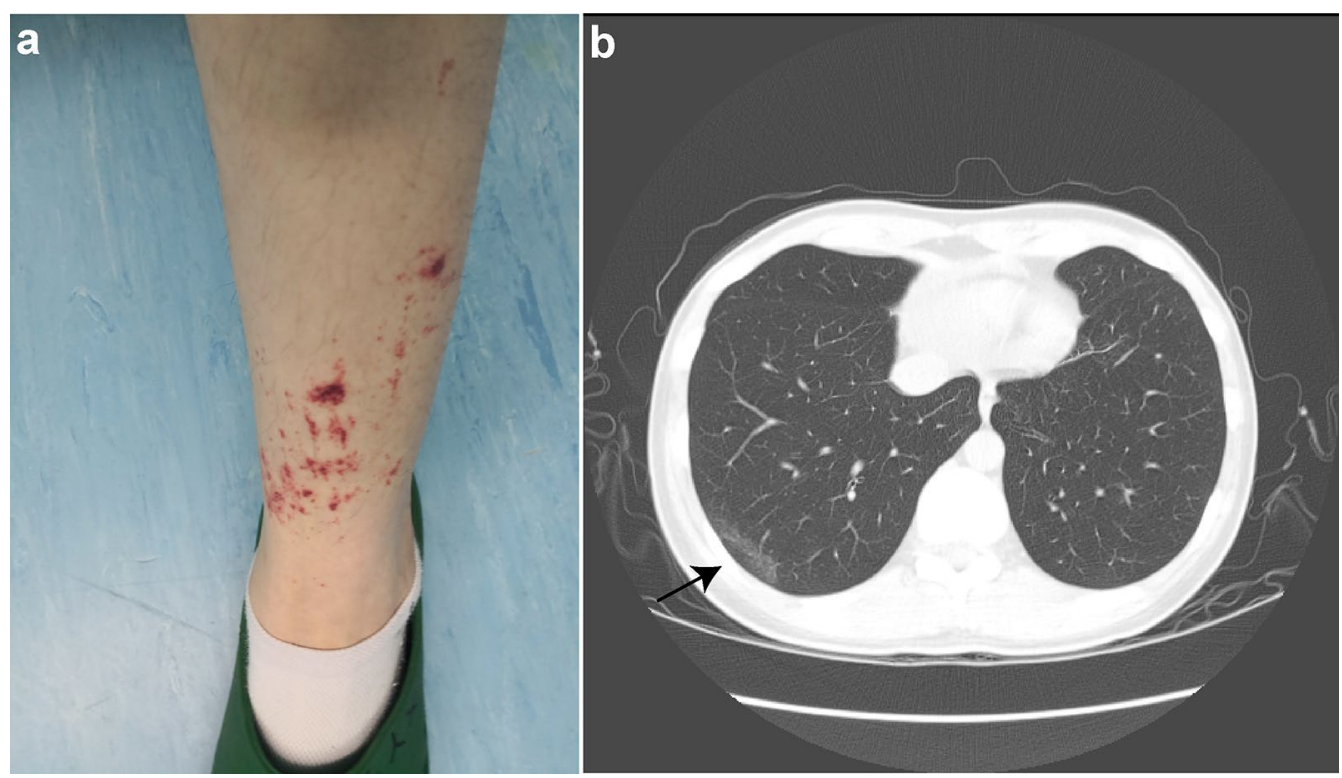

Fig. 1 A Skin lesion presenting as purpura of the left lower limb. B Chest CT scan showed a subpleural patchy shadow in the posterior basal segment of the right lower lobe (black arrow) 

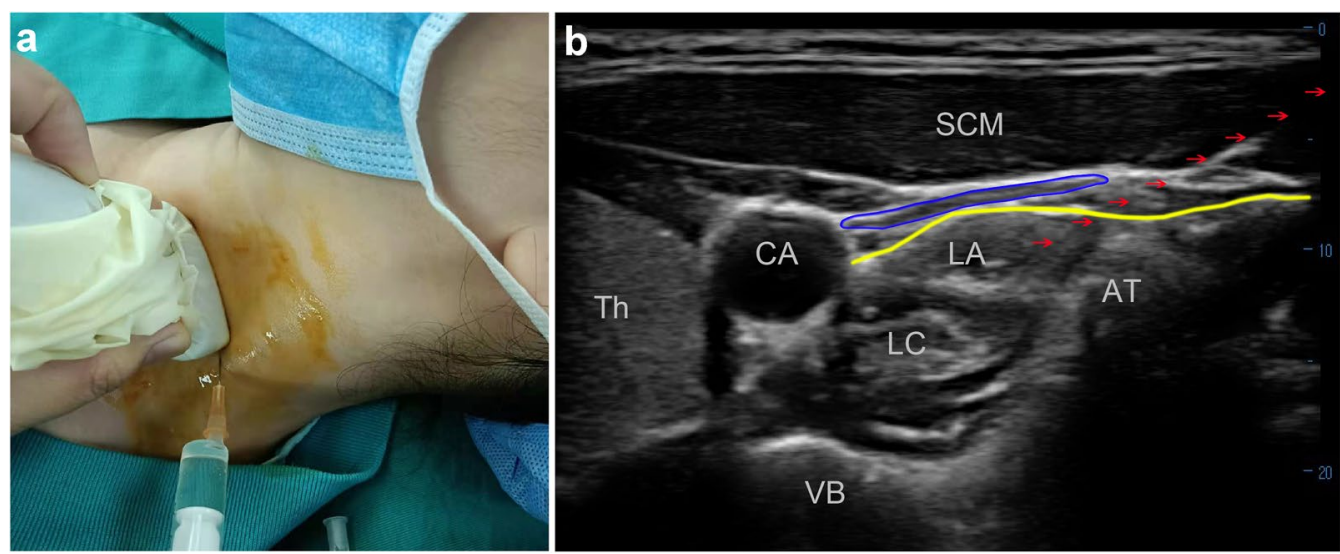

Fig. 2 Transducer position and corresponding ultrasound image of the stellate ganglion block (SGB). A Performance of the SGB using transverse scanning with needle in-plane approach. B Ultrasound images for the SGB. The internal jugular vein was compressed (blue circle); the yellow line represents the prevertebral fascia, and the red arrow indicates the in-plane needle path. $L C$ longus colli, SCM sternocleidomastoid muscle, $L A$ local anesthetic, Th thyroid gland, CA carotid arter, AT anterior tubercle of C6 transverse process, VB C6 vertebral body

reported. Unfortunately, recurrent symptoms were triggered by a negative emotional event, and inhaled corticosteroid therapy was reinstituted to control asthma. A second course of SGBs conferred satisfactory symptomatic relief. The prednisone acetate dose was gradually reduced to $10 \mathrm{mg} /$ day, with cyclophosphamide added at a daily maintenance dose of $50 \mathrm{mg}$ over a 3-month period with no observed recurrence.

\section{Discussion}

Our patient suffered from EGPA involving the respiratory and digestive systems, peripheral nerves, and skin; and experienced a favorable response to glucocorticoidbased induction therapy. However, glucocorticoid dose reduction was difficult, which is in consistent with the observation that EGPA patients frequently relapse during glucocorticoid tapering [4]. To our knowledge, this is the first report of the use of SGB to alleviate EGPA-related symptoms. The mechanism of action is undetermined, and we propose the following possibilities.

Firstly, SGBs may alleviate symptoms and organ damage through vasodilation. The typical pathological feature of EGPA is necrotizing small vessel vasculitis accompanied by eosinophilic infiltrates and perivascular and extravascular granulomas, leading to ischemia of the involved organs [4]. SGB averts sympathetic innervation, resulting in peripheral vasodilatation and increased perfusion [11]; consequently, it is widely used to treat a variety of ischemic disorders of the head, chest, face, and upper extremities. Furthermore, SGB may directly suppress inflammation and edema of the vascular wall [8].
Secondly, SGB significantly impacts conditions linked to immune dysfunction [12]. Though EGPA is considered a classical $\mathrm{T}$ helper (Th) 2-response mediated disease, Th1 response cannot be ignored [13]. Eosinophils promote inflammation by releasing cytotoxic granule proteins and lipid mediators [4]. Some Th1-related cytokines are also released during this process, and include interferon- $\gamma$, IL-1 $\beta$, IL- 6 and IL-8, which further exacerbate vasculitis and tissue injury $[13,14]$. Several studies have demonstrated that SGB led to decreases in concentrations of Th1 cytokines, including IL-1 $\beta$, IL-6, TNF- $\alpha$ and IL- 8 in patients with trauma or chronic ulcerative colitis [15-17]. Therefore, we speculated that SGB could also reduce the tissue damage caused by Th1 cytokines in EGPA. Next, it has been reported that SGB led to reductions of peripheral blood eosinophilia and serum IgE levels in a patient with atopic dermatitis [18], which are also treatment goals of the clinical management of EGPA. Moreover, a recent published hypothesis believes that the effects of the SGB on the immune system are complex and are best represented as immuno-modulating, rather than being simply suppressing or stimulating [12].

Finally, as with other autoimmune diseases [1922], stress may trigger disease flares in patients with EGPA. Relapse was triggered by a negative emotional event experienced by our patient. SGB has been used with some success to treat multiple psychiatric conditions, including anxiety and post-traumatic stress disorder (PTSD). The mechanism of action in psychiatric conditions is unclear [5, 23], but may involve centripetal neuronal connections between the stellate ganglia and deep brain regions such as the 
insula, amygdala, and hippocampus, which regulate the formation of cognition, memory, and behaviors [24]. On the other hand, sleep disturbance is common during anxiety and in PTSD patients. SGB may reestablish the normal melatonin circadian rhythm by interrupting the sympathetic cycle [25]. Our patient also reported improvements in mood and sleep after SGBs.

In summary, our case suggests that ultrasoundguided SGB may represent a simple and safe method to relieve symptoms and impede disease progression in EGPA patients, and may lead to wider usage of the technique in immune-linked disorders, such as multiple vasculitides, Sjogren's syndrome, and scleroderma. Further investigation is needed to evaluate efficacy and to elucidate the mechanism of action of SGB in the therapy of immune-linked disorders.

\section{Abbreviations}

EGPA: Eosinophilic granulomatosis with polyangiitis; SGB: Stellate ganglion block; PTSD: Post-traumatic stress disorder.

\section{Acknowledgements}

None.

\section{Authors' contributions}

YX collected the case's material. DM, RS and YY performed most of stellate ganglion block, and DM was involved in writing the first draft manuscript. HL, XS and LW participated in the disease diagnosis, discussion and interpretation. YW designed the therapy and wrote the final manuscript. All authors read and approved the final manuscript.

\section{Funding}

This work was supported by the Beijing Municipal Science \& Technology Commission, PR China (Z181100001718222).

\section{Availability of data and materials}

Data sharing is not applicable to this article as no datasets were generated or analyzed during this case report.

\section{Declarations}

\section{Ethics approval and consent to participate}

Informed consent was obtained from the patient to use her data.

\section{Consent for publication}

Consent for publication was obtained from the patient.

\section{Competing interests}

The authors declare that they have no competing interests.

\section{Author details}

'Department of Anesthesiology and Pain Medicine, Beijing Chaoyang Hospital, Capital Medical University, Beijing, China. ${ }^{2}$ Operating Room, Beijing Chaoyang Hospital, Capital Medical University, Beijing 100020, China. ${ }^{3}$ Department of Rheumatology and Immunology, Beijing Chaoyang Hospital, Capital Medical University, Beijing, China. ${ }^{4}$ Department of Rheumatology and Immunology, Peking Union Medical College Hospital, Chinese Academy of Medical Sciences, Beijing, China.

Received: 9 May 2021 Accepted: 2 February 2022

Published online: 19 February 2022

\section{References}

1. Silva M, Roufosse F. Oral corticosteroid use for the treatment of chronic eosinophilic disease: a patient's and his physician's experience. Adv Ther. 2019;36(10):2558-66.

2. Robson JC, Dawson J, Cronholm PF, Ashdown S, Easley E, Kellom KS, et al. Patient perceptions of glucocorticoids in anti-neutrophil cytoplasmic antibody-associated vasculitis. Rheumatol Int. 2018:38(4):675-82.

3. Wechsler ME, Akuthota P, Jayne D, Khoury P, Klion A, Langford CA, et al. Mepolizumab or placebo for eosinophilic granulomatosis with polyangiitis. N Engl J Med. 2017;376(20):1921-32.

4. Furuta S, Iwamoto T, Nakajima H. Update on eosinophilic granulomatosis with polyangiitis. Allergol Int. 2019;68(4):430-6.

5. Baig S, Moon JY, Shankar H. Review of sympathetic blocks: anatomy, sonoanatomy, evidence, and techniques. Reg Anesth Pain Med. 2017:42(3):377-91.

6. Sahin OF, Tarikci Kilic E, Aksoy Y, Kaydu A, Gokcek E. The importance of perfusion index monitoring in evaluating the efficacy of stellate ganglion blockage treatment in Raynaud's disease. Libyan J Med. 2018;13(1):1422666

7. Viswanath O, Peck J, Gill JS. An atypical presentation of Raynaud's disease. Med Princ Pract. 2019;28(4):394-6.

8. Noma N, Kamo H, Nakaya Y, Dezawa K, Young A, Khan J, et al. Stellate ganglion block as an early intervention in sympathetically maintained headache and orofacial pain caused by temporal arteritis. Pain Med. 2013;14(3):392-7.

9. Punj J. Multiple bilateral ultrasound-guided stellate ganglion blocks to treat acute vasculitis in a recently diagnosed patient of systemic lupus erythematosus. Indian J Anaesth. 2019;63(10):851-5.

10. Martini H. Stellate ganglion block in bronchial asthma. Dtsch Med Wochenschr. 1952;77(21):683-5.

11. Kubota K, Sunada K. Changes in blood flow at the mandibular angle and Horner syndrome in a rat model of superior cervical ganglion block. J Dent Anesth Pain Med. 2018:18(2):105-10

12. Lipov E, Gluncic V, Lukic IK, Candido K. How does stellate ganglion block alleviate immunologically-linked disorders? Med Hypotheses. 2020:144:110000

13. Khoury P, Grayson PC, Klion AD. Eosinophils in vasculitis: characteristics and roles in pathogenesis. Nat Rev Rheumatol. 2014;10(8):474-83.

14. Vaglio A, Buzio C, Zwerina J. Eosinophilic granulomatosis with polyangiitis (Churg-Strauss): state of the art. Allergy. 2013;68(3):261-73.

15. Liu MH, Tian J, Su YP, Wang T, Xiang Q, Wen L. Cervical sympathetic block regulates early systemic inflammatory response in severe trauma patients. Med Sci Monit. 2013;19:194-201.

16. Zhao HY, Yang GT, Sun NN, Kong Y, Liu YF. Efficacy and safety of stellate ganglion block in chronic ulcerative colitis. World J Gastroenterol. 2017:23(3):533-9.

17. Yang X, Shi Z, Li X, Li J. Impacts of stellate ganglion block on plasma NF-kappaB and inflammatory factors of TBI patients. Int J Clin Exp Med. 2015:8(9):15630-8.

18. Wajima Z, Harada S, Nakajima Y, Shitara T, Kobayashi N, Kadotani $\mathrm{H}$, et al. A case of atopic dermatitis treated with stellate ganglion block - the change of serum IgE and blood eosinophil levels. Masui. 1995:44(8):1135-8.

19. Bai R, Liu S, Zhao Y, Cheng Y, Li S, Lai A, et al. Depressive and anxiety disorders in systemic lupus erythematosus patients without major neuropsychiatric manifestations. J Immunol Res. 2016;2016:2829018.

20. Pawlak CR, Witte T, Heiken H, Hundt M, Schubert J, Wiese B, et al. Flares in patients with systemic lupus erythematosus are associated with daily psychological stress. Psychother Psychosom. 2003;72(3):159-65.

21. Golemati CV, Mavragani CP, Lionaki S, Karaiskos D, Moutsopoulos HM. Stress and disease onset in antineutrophil cytoplasmic antibodyassociated vasculitis. Front Psychiatry. 2017;8:286.

22. Porcelli B, Pozza A, Bizzaro N, Fagiolini A, Costantini MC, Terzuoli L, et al. Association between stressful life events and autoimmune diseases: a systematic review and meta-analysis of retrospective case-control studies. Autoimmun Rev. 2016:15(4):325-34.

23. Lipov E. Successful use of stellate ganglion block and pulsed radiofrequency in the treatment of posttraumatic stress disorder: a case report. Pain Res Treat. 2010;2010:963948. 
24. Navaie M, Keefe MS, Hickey AH, Mclay RN, Ritchie EC, Abdi S. Use of stellate ganglion block for refractory post-traumatic stress disorder: a review of published cases. J Anesth Clin Res. 2014;5(403):2.

25. Uchida K, Tateda T, Hino H. Novel mechanism of action hypothesized for stellate ganglion block related to melatonin. Med Hypotheses. 2002;59(4):446-9.

\section{Publisher's Note}

Springer Nature remains neutral with regard to jurisdictional claims in published maps and institutional affiliations.

- fast, convenient online submission

- thorough peer review by experienced researchers in your field

- rapid publication on acceptance

- support for research data, including large and complex data types

- gold Open Access which fosters wider collaboration and increased citations

- maximum visibility for your research: over $100 \mathrm{M}$ website views per year

At BMC, research is always in progress.

Learn more biomedcentral.com/submissions 